Check for updates

Cite this: RSC Adv., 2018, 8, 34573

\title{
High-capacity and selective ammonium removal from water using sodium cobalt hexacyanoferrate $\uparrow$
}

\author{
Yong Jiang, ${ }^{\text {ab }}$ Kimitaka Minami, ${ }^{\text {b }}$ Koji Sakurai, ${ }^{\mathrm{b}}$ Akira Takahashi, ${ }^{\mathrm{b}}$ Durga Parajuli, ${ }^{\mathrm{b}}$ \\ Zhongfang Lei, (D) a Zhenya Zhang (iD a and Tohru Kawamoto (iD *b
}

A new $\mathrm{NH}_{4}{ }^{+}$adsorbent with high capacity and selectivity, sodium cobalt(॥) hexacyanoferrate(॥) (NaCoHCF, $\left.\mathrm{Na}_{y} \mathrm{Co}(॥)\left[\mathrm{Fe}^{2+}(\mathrm{CN})_{6}\right]_{x} \cdot \mathrm{zH}_{2} \mathrm{O}\right)$, was prepared. The adsorption performance was investigated by varying the mixing ratio of $\left[\mathrm{Fe}(\mathrm{CN})_{6}\right]^{4-}$ to $\mathrm{Co}^{2+}$ during synthesis, $R_{\text {mix }}$. The ammonia capacity was found to be proportional to $R_{\text {mix }}$ indicating that the $\mathrm{NH}_{4}{ }^{+}$capacity can be increased by increasing the $\mathrm{Na}^{+}$-ion content in NaCoHCF. To conduct a detailed study, we prepared homogeneous nanoparticles by flow synthesis using a micromixer with $R_{\text {mix }}=1.00$. Even on the addition of a saline solution $(\mathrm{NaCl})$ with an $\mathrm{Na}^{+}$-ion concentration of $9350 \mathrm{mg} \mathrm{L}{ }^{-1}$, the capacity was maintained: $q_{\max }=4.28 \mathrm{~mol} \mathrm{~kg}^{-1}$. Using Markham-Benton analysis, the selectivity factor, defined by the ratio of equilibrium constants for $\mathrm{NH}_{4}{ }^{+}$ to that for $\mathrm{Na}^{+}$, was calculated to be $\alpha=96.2$, and $4.36 \mathrm{~mol} \mathrm{~kg}^{-1}$ was found to be the maximum capacity. The high selectivity of $\mathrm{NaCoHCF}$ results in good $\mathrm{NH}_{4}{ }^{+}$-adsorption performance, even from seawater. In comparison with other adsorbents under the same conditions and even for a $\mathrm{NH}_{4} \mathrm{Cl}$ solution, $\mathrm{NaCOHCF}$ showed the highest capacity. Moreover, the coexisting $\mathrm{Na}^{+}$caused no interference with the adsorption of ammonium by $\mathrm{NaCoHCF}$, whereas the other adsorbents adsorbed ammonia only slightly from the saline solution. We also found that the pores for $\mathrm{NH}_{4}{ }^{+}$adsorption changed their sizes and shapes after adsorption.

Received 5th September 2018
Accepted 1st October 2018

DOI: $10.1039 / \mathrm{c} 8 \mathrm{ra07421f}$

rsc.li/rsc-advances emissions from the open ocean represent $3.8 \mathrm{Tg} \mathrm{N}$ per year, 35\% of the total natural emissions. ${ }^{5}$

In fact, various nations have set standards for ammonia in effluent or environmental water. For example, the U.S. Environmental Protection Agency (EPA) lowered the limit in 2013 for aquatic life in ambient water bodies to 17 and $1.9 \mathrm{mg} \mathrm{L}^{-1}$ total ammonia nitrogen one-hour and 30 day averages, respectively. ${ }^{6}$ China and India have also established standards for effluents of 15-50 and $50 \mathrm{mg} \mathrm{L}^{-1}$ ammonium nitrogen., ${ }^{7,8}$ Reducing the ammonium concentration is also important for biogasification technology with anaerobic digestion because the digestion is inhibited by high concentrations of ammonium. Depending on the conditions, $1500-5000 \mathrm{mg} \mathrm{L}^{-1}$ of total ammonium nitrogen can cause the slow down or failure of digestion. ${ }^{9,10}$ For the removal of $\mathrm{NH}_{4}{ }^{+}$from wastewater or digestion liquids, methods for the selective removal of $\mathrm{NH}_{4}{ }^{+}$are necessary because various ions coexist in these solutions.

For the uptake of $\mathrm{NH}_{4}{ }^{+}$, removal with an adsorbent is an easily controllable and highly efficient method. Strong acid cation (SAC) exchange resins, analogs of Amberlite IR-120 (Alfa Aesar, UK), show the highest adsorption capacity, reaching $5.34 \mathrm{~mol} \mathrm{~kg}^{-1}$ for aqueous solution without coexisting cations and using glass-packed bed columns. ${ }^{11}$ Nevertheless, SAC resins have low selectivity to $\mathrm{NH}_{4}{ }^{+}$when other competing ions are present. He et al. studied alkaline-activated and lanthanumimpregnated zeolites ${ }^{12}$ and found a maximum adsorption

${ }^{a}$ Graduate School of Life and Environmental Sciences, University of Tsukuba, 1-1-1, Tennodai, Tsukuba, Ibaraki 305-8572, Japan

${ }^{b}$ Nanomaterials Research Institute, National Institute of Advanced Industrial Science and Technology (AIST), 1-1-1 Higashi, Tsukuba 305-8565, Japan. E-mail: tohru. kawamoto@aist.go.jp

$\dagger$ Electronic supplementary information (ESI) available. See DOI: $10.1039 / \mathrm{c} 8 \mathrm{ra} 07421 \mathrm{f}$ 
capacity, $q_{\max }$, of $1.54 \mathrm{~mol} \mathrm{~kg}^{-1}$ in a pure water solution. However, the removal efficiency, $P_{\mathrm{R}}$, decreased from $90 \%$ to $36 \%$ in the presence of $\mathrm{Na}^{+}$. Soetardji et al. reported that sodium-hydroxide-modified zeolite mordenite has $q_{\max }=$ $3.0 \mathrm{~mol} \mathrm{~kg}{ }^{-1}$ in aqueous solution and that $P_{\mathrm{R}}$ decreased from $81 \%$ to $66.9 \%$ when competing with other ions. ${ }^{13}$ Guaya et al. studied a hydrated aluminum-oxide-modified zeolite, ${ }^{\mathbf{1 4}}$ which showed $q_{\text {max }}=2.14 \mathrm{~mol} \mathrm{~kg}^{-1}$ in aqueous solution and $P_{\mathrm{R}}=12 \%$ with coexisting $\mathrm{Na}^{+}$ions.

Thus, conventional adsorbents have lower selectivity. As mentioned above, for the removal of $\mathrm{NH}_{4}{ }^{+}$from wastewater or the digestion liquids, adsorbents with high-selectivity are crucial. In particular, for digestion liquids, a large capacity is also essential because the $\mathrm{NH}_{4}{ }^{+}$concentration is quite high. For these reasons, the development of new adsorbents with both large capacity and high selectivity is desirable.

In our earlier study, we found that potassium copper hexacyanoferrate, KCuHCF, has a high ammonium adsorption capacity of $1.94 \mathrm{~mol} \mathrm{~kg}^{-1}$, as well as high selectivity for dissolved ammonia. ${ }^{15}$ Potassium copper hexacyanoferrate (KCuHCF), a metal hexacyanoferrate (MHCF), is a Prussian blue analog. MHCFs have the chemical composition of $\mathrm{A}_{y} \mathrm{M}$ $\left[\mathrm{Fe}(\mathrm{CN})_{6}\right]_{1-x} \cdot z \mathrm{H}_{2} \mathrm{O}$, where $\mathrm{A}$ and $\mathrm{M}$, respectively, denote alkali and transition metals, and $x$ indicates the concentration of $\left[\mathrm{Fe}(\mathrm{CN})_{6}\right]$ vacancies. With respect to MHCFs, many researchers have studied their use in catalysis, ${ }^{\mathbf{1 6 - 1 8}}$ electrodes in secondary batteries, ${ }^{19-22}$ electrochromism, ${ }^{23-27}$ sensors, ${ }^{28,29}$ gas storage,${ }^{30-32}$ photomagnets, ${ }^{33-35}$ and adsorbents for radioactive $\mathrm{Cs}^{+}$ions. ${ }^{36-40}$ The ionic radii of hydrated $\mathrm{Cs}$ and $\mathrm{NH}_{4}$ are similar (3.29 and 3.31 ^, respectively). Therefore, assuming a size-based adsorption model, MHCFs could also have substantial adsorption capability for $\mathrm{NH}_{4}{ }^{+} \cdot{ }^{41}$

The $\mathrm{NH}_{4}{ }^{+}$-adsorption mechanism is affected by the porous network in MHCFs. The crystal structure of MHCF is shown in Fig. 1, where two kinds of adsorption sites exist. One is an interstitial site, a cubic confined space surrounded by eight metal sites and twelve cyano-groups. Its pore size is less than $0.5 \mathrm{~nm}$. The other is a vacancy site, represented as $\left[\mathrm{Fe}(\mathrm{CN})_{6}\right]$ vacancies. In the case of $\mathrm{KCuHCF}$, both $\mathrm{K}^{+}$and $\mathrm{NH}_{4}{ }^{+}$are located in the interstitial sites, as shown by Rietveld analysis of the X-ray diffraction (XRD) patterns. ${ }^{15}$ In addition, $\mathrm{NH}_{4}{ }^{+}$is adsorbed via the ion-exchange with the $\mathrm{A}^{+}$ions $\left(\mathrm{K}^{+}\right.$in the case of KCuHCF). ${ }^{15}$ Therefore, to enhance the adsorption capacity, $\left[\mathrm{Fe}(\mathrm{CN})_{6}\right]$ vacancies should be eliminated. This is because the number of $\mathrm{A}^{+}$ions increases as the number of vacancies decreases because of charge balance. The other reason is that the vacancy site does not play a role in $\mathrm{NH}_{4}{ }^{+}$adsorption.

Based on these considerations, in this paper, we investigated the use of another MHCF, sodium cobalt hexacyanoferrate (NaCoHCF), to enhance the adsorption capacity. The most important difference between KCuHCF and NaCoHCF is the difference between $\mathrm{Cu}$ and Co. In the case of KCuHCF, KCuHCF with fewer $\left[\mathrm{Fe}(\mathrm{CN})_{6}\right]^{4-}$ vacancies causes material instability in the aqueous solution. ${ }^{42}$ However, with substitution with Co, the introduction of a small number of $\left[\mathrm{Fe}(\mathrm{CN})_{6}\right]^{4-}$ vacancies becomes possible. Additionally, the affinity of MHCF for the mono-cation is known to depend on the hydrated radius,

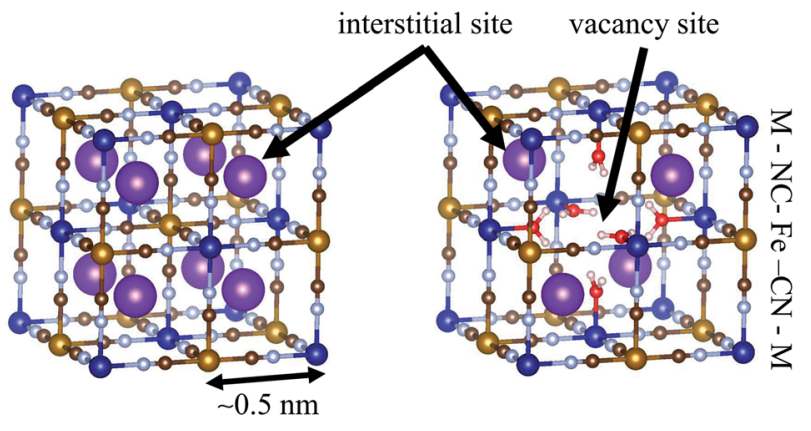

$$
\mathrm{A}_{2} \mathrm{M}\left[\mathrm{Fe}(\mathrm{CN})_{6}\right] \cdot z \mathrm{H}_{2} \mathrm{O}(\mathrm{x}=0) \quad \mathrm{AM}\left[\mathrm{Fe}(\mathrm{CN})_{6}\right]_{0.75} \cdot z \mathrm{H}_{2} \mathrm{O}(\mathrm{x}=0.25)
$$

Fig. 1 The crystal structure of metal hexacyanoferrate (MHCF, Ay $\left.\left[\mathrm{Fe}(\mathrm{CN})_{6}\right]_{1-x} \cdot z \mathrm{H}_{2} \mathrm{O}\right)$ with different vacancy concentrations, $x$. Purple spheres represent $\mathrm{A}^{+}$cations, the ion-exchange species in $\mathrm{NH}_{4}^{+}$ adsorption.

implying that utilization of $\mathrm{Na}^{+}$instead of $\mathrm{K}^{+}$can increase the $\mathrm{NH}_{4}{ }^{+}$adsorption performance.

Our study has two parts. The first is a compositiondependent study. Five kinds of NaCoHCF-nanoparticles (NaCoHCF-NPs), $\mathrm{Na}_{y} \mathrm{Co}\left[\mathrm{Fe}(\mathrm{CN})_{6}\right]_{x} \cdot \mathrm{zH}_{2} \mathrm{O}$, were synthesized by changing the molar concentration ratio of the reagent solution $\left(R_{\text {mix }}\right)$ using a batch method. The second part is a detailed study of $R_{\text {mix }}=1.00$. Quantitative analysis into the adsorption capacity and selectivity was conducted. The changes to the crystal structure are also discussed. By comparison with earlier studies, we found that our NaCoHCF exhibits the a very high capacity when using the batch-adsorption method. Particularly for $\mathrm{NH}_{4}{ }^{+}$adsorption from saline solutions, the benefits of NaCoHCF are enhanced by its high selectivity. We also demonstrate its potential for recyclability.

\section{Experimental section}

\subsection{Synthesis of NaCoHCF-NPs}

First, NaCoHCF-NPs with compositions of $\mathrm{Na}_{4 x-2} \mathrm{Co}\left[\mathrm{Fe}(\mathrm{CN})_{6}\right]_{x}$ (water omitted) were prepared according to the following chemical reaction.

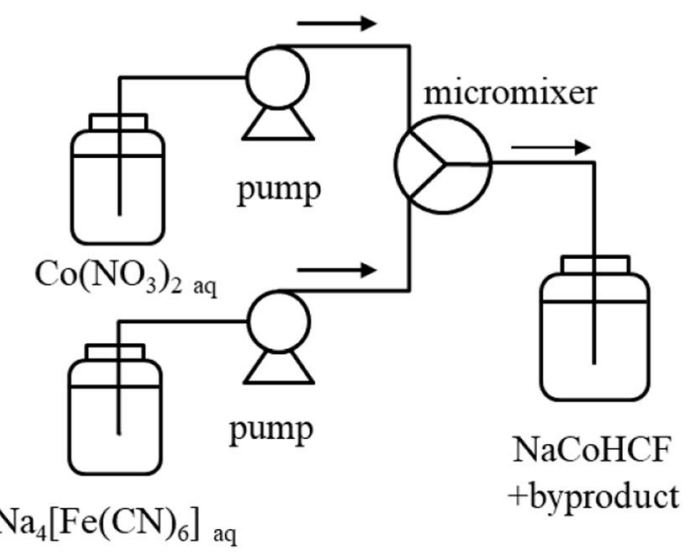

Scheme 1 Schematic view of the synthesis of $\mathrm{NaCoHCF}$ by a micromixer 


$$
\begin{aligned}
\mathrm{Co}\left(\mathrm{NO}_{3}\right)_{2}+x \mathrm{Na}_{4}\left[\mathrm{Fe}(\mathrm{CN})_{6}\right] & \rightarrow \mathrm{Na}_{4 x-2} \mathrm{Co}\left[\mathrm{Fe}(\mathrm{CN})_{6}\right]_{x} \\
& +2 \mathrm{NaNO}_{3}
\end{aligned}
$$

To study the composition dependence, the NaCoHCF-NPs were synthesized using a batch method by mixing two aqueous solutions of $\mathrm{Na}_{4}\left[\mathrm{Fe}(\mathrm{CN})_{6}\right] \cdot 10 \mathrm{H}_{2} \mathrm{O}$ (Wako Pure Chemical Ind., Ltd.) and $\mathrm{CoCl}_{2} \cdot 6 \mathrm{H}_{2} \mathrm{O}$ (special grade from Wako Pure Chemical Ind., Ltd.) with different molar concentration ratios $\left(R_{\text {mix }}=0.50,0.75,1.00,1.50\right.$, and 2.00$)$. Here, $R_{\text {mix }}$ represents the mixing ratio of the concentration of $\left[\mathrm{Fe}(\mathrm{CN})_{6}\right]^{4-}$ to that of $\mathrm{Co}^{2+}$. The suspension was shaken using a multi shaker (SI-300C; AS One Corp.) for $3 \mathrm{~min}$ at $1700 \mathrm{rpm}$ and room temperature. After shaking, the slurry solutions were centrifuged. The slurries were washed at least five times with Milli-Q water. They were dried under vacuum at $60{ }^{\circ} \mathrm{C}$ for $48 \mathrm{~h}$.

For detailed studies conducted with a fixed composition, we prepared NaCoHCF-NP samples using a flow synthesis method to guarantee the homogeneity of the particle size and chemical composition. ${ }^{36}$ The NaCoHCF-NPs, denoted Flow1.00 , was synthesized by mixing $0.4 \mathrm{~mol} \mathrm{~L}^{-1}$ solutions of the $\mathrm{Na}_{4}\left[\mathrm{Fe}(\mathrm{CN})_{6}\right] \cdot 10 \mathrm{H}_{2} \mathrm{O}$ and $\mathrm{Co}\left(\mathrm{NO}_{3}\right)_{2} \cdot 6 \mathrm{H}_{2} \mathrm{O}$ (special grade from Wako Pure Chemical Ind., Ltd.) in a Y-type micro-mixer with a hole of $\Phi 250 \mu \mathrm{m}$, as shown schematically in Scheme 1 . The mixed concentrations were the same as those for Batch1.00. The flow rates of the two solutions were set to be equal.

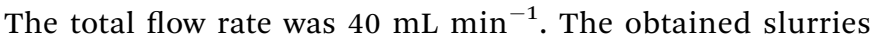
were washed using a hollow fiber rinse system (DBW-24; OCT Science Co., Ltd.) to remove the $\mathrm{NaNO}_{3}$ byproduct. Then, the $\mathrm{NaCoHCF}-\mathrm{NPs}$ were dried in vacuum at $60{ }^{\circ} \mathrm{C}$ for $72 \mathrm{~h}$.

\subsection{Characterization of NaCoHCF-NPs}

The crystal structures of Flow-1.00 were studied before and after $\mathrm{NH}_{4}{ }^{+}$adsorption using an X-ray diffractometer (D2 Phaser; Bruker Analytik GmbH, Germany) with $\mathrm{Cu} \mathrm{K \alpha}(\lambda=1.54 \AA)$ radiation in the $2 \theta$ range of $5-60^{\circ}$ at $30 \mathrm{kV}$ and $10 \mathrm{~mA}$. A Si (311) double-crystal monochromator was used to monochromatize the incident beam while reducing the high harmonics of the monochromatic beam. The XRD patterns were analyzed using the Pawley method to determine the space group and the lattice constants. For adsorption, a $500 \mathrm{mg} \mathrm{L}^{-1} \mathrm{NH}_{4}^{+}$aqueous solution was used. Other conditions are described in Section 2.3. The crystallite sizes were estimated using Scherrer analysis of the XRD patterns, assuming a Scherrer constant of $0.94 .{ }^{43}$ Sample images were obtained using a field-emission scanning electron microscope (FE-SEM, S-4800; Hitachi Hitec Corp.) with $5 \mathrm{kV}$ accelerating voltage after Pt-Pd coating using an ion sputter coater (E-1030; Hitachi Ltd., Japan). The chemical compositions and leaching concentration of $\mathrm{CN}^{-}$into treated water were determined using a Microwave Plasma-Atomic Emission Spectrometer (MP-AES, 4100; Agilent Technologies Inc., USA) with pre-decomposition using microwaves (MW, Multiwave 3000; PerkinElmer Inc., USA). The hydration numbers in each sample were ascertained through thermogravimetric analysis (Thermo Plus EVO2; Rigaku Corp.). The specific surface areas of several samples were estimated by fitting the Brunauer, Emmett, and
Teller (BET) equation to the $\mathrm{N}_{2}$ adsorption isotherms obtained at $77 \mathrm{~K}$. The typical pre-treatment condition was $100{ }^{\circ} \mathrm{C}$ for $24 \mathrm{~h}$.

\section{$2.3 \mathrm{NH}_{4}^{+}$adsorption tests}

To evaluate the composition dependence, a batch-shaking method was used to evaluate the $\mathrm{NH}_{4}{ }^{+}$adsorption capacity of the NaCoHCF-NPs, as shown schematically in Fig. S1(a). $\dagger$ The method was conducted as follows: $40 \mathrm{mg}$ of an NaCoHCF sample (Batch-0.50, 0.75, 1.00, 1.50, or 2.00) was added to a $40 \mathrm{~mL}$ aqueous solution of $\mathrm{NH}_{4} \mathrm{Cl}$ with a $\mathrm{NH}_{4}{ }^{+}$concentration of $90 \mathrm{mg} \mathrm{L}^{-1}$. The suspension was shaken using a multi shaker (SI-300C; AS One Corp.) at $600 \mathrm{rpm}$ for $180 \mathrm{~min}$ at $30{ }^{\circ} \mathrm{C}$. After shaking, the supernatant was obtained via centrifuging and further separation using a $0.45 \mu \mathrm{m}$ filter (MCE syringe filter; Membrane Solutions). The $\mathrm{NH}_{4}{ }^{+}$concentration in the supernatant was evaluated using ion chromatography (IC, 883 Basic IC plus; Metrohm AG).

For a detailed study using a fixed composition, the conditions were the same except that the $\mathrm{NH}_{4}{ }^{+}$concentration was changed to 1-1000 $\mathrm{mg} \mathrm{L}^{-1}$ in the $\mathrm{NH}_{4} \mathrm{Cl}$ aqueous solution and saline solution. The saline solution was prepared with $9350 \mathrm{mg} \mathrm{L}^{-1}$ of $\mathrm{Na}^{+}$ions ( $\mathrm{NaCl}$, special grade from Wako Pure Chemical Ind., Ltd.), where the $\mathrm{Na}^{+}$concentration was set to match that of Daigo's artificial seawater SP (Wako Pure Chemical Ind., Ltd.), $9348 \mathrm{mg} \mathrm{L}^{-1}$.

For comparison, the $\mathrm{NH}_{4}{ }^{+}$adsorption properties of synthetic zeolite (A-3, powder, through $75 \mu \mathrm{m}$, Wako Pure Chemical Industries Ltd.), sepiolite (Omi Mining Co., Ltd., Japan), and Amberlite IR-120 (H) (Alfa Aesar, UK) were also investigated. All samples were produced with no pretreatment, such as drying, before the adsorption testing. The $\mathrm{NH}_{4}{ }^{+}$concentration in the aqueous $\mathrm{NH}_{4} \mathrm{Cl}$ and in the saline solution were both set to $500 \mathrm{mg} \mathrm{L}{ }^{-1}$. To remove the effects of $\mathrm{Na}^{+}$from the $\mathrm{NH}_{4}^{+}$ measurements, all saline solutions were diluted and distilled to trap only $\mathrm{NH}_{4}^{+}$ions before measurement by IC. When the concentration of $\mathrm{NH}_{4}{ }^{+}$was higher than $150 \mathrm{mg} \mathrm{L}{ }^{-1}$ after distillation, the solutions were diluted five times for IC measurement. Other solutions were measured directly by IC.

\subsection{Evaluation of recyclability}

The potential for recyclability was also investigated. The experimental setup is shown in Fig. S1(b). $\uparrow$ A membrane filter with NaCoHCF-NPs was prepared for the flow test. The Flow1.00 powder was mixed with $2 \mathrm{~mL}$ Milli-Q $\left(3.76 \mathrm{mg} \mathrm{mL}^{-1}\right.$ ) using an ultrasonic cleaner (W-113MK-II; Honda). Then, $100 \mu \mathrm{L}$ solutions were dropped on the membrane filter $(\Phi 25 \mathrm{~mm}, 0.45$ $\mu \mathrm{m}$ pore size, JHWP01300; Merck), followed by drying at $60{ }^{\circ} \mathrm{C}$ for $2 \mathrm{~min}$. Thus prepared, the solutions were set on a circular plastic plate of $\Phi 25 \mathrm{~mm}$ with a hole of $\Phi 5 \mathrm{~mm}$ in the middle. They were pasted on the film for effective adsorption-desorption. An FT-IR spectrometer (iD1 transmission iS5; Nicolet Biomedical Inc.) was used to confirm adsorption and desorption of $\mathrm{NH}_{4}^{+}$. For the adsorption test, the $\mathrm{NH}_{4}{ }^{+}$solution of $500 \mathrm{mg} \mathrm{\textrm {L } ^ { - 1 }}$ was flowed through the NaCoHCF-NP-dipped membrane for $30 \mathrm{~min}$ at the rate of $0.2 \mathrm{~mL} \mathrm{~min}^{-1}$. For the 
Table 1 The mixing ratio, $R_{\text {mix }}$ in synthesis and the chemical compositions and crystal structure of the NaCoHCF-NP samples

\begin{tabular}{|c|c|c|c|c|c|c|c|c|c|}
\hline Samples & $R_{\text {mix }}$ & $x$ & $y$ & $z$ & Chemical compositions & Space group & $a(\AA)$ & $b(\AA)$ & $c(\AA)$ \\
\hline \multirow[t]{2}{*}{ Batch-0.50 } & \multirow[t]{2}{*}{0.50} & \multirow[t]{2}{*}{0.57} & \multirow[t]{2}{*}{0.49} & \multirow[t]{2}{*}{3.64} & \multirow[t]{2}{*}{$\mathrm{Na}_{0.49} \mathrm{Co}_{1.00}\left[\mathrm{Fe}(\mathrm{CN})_{6}\right]_{0.57} \cdot 3.64 \mathrm{H}_{2} \mathrm{O}$} & $P 2_{1} / m$ & 11.83 & 9.52 & 7.47 \\
\hline & & & & & & $R \overline{3} c$ & 12.77 & 12.77 & 29.06 \\
\hline & & 0.63 & 0.74 & 3.41 & $\mathrm{Na}_{0.74} \mathrm{Co}_{1.00}\left[\mathrm{Fe}(\mathrm{CN})_{6}\right]_{0.63} \cdot 3.41 \mathrm{H}_{2} \mathrm{O}$ & $R \overline{3} c$ & 12.97 & 12.97 & 25.77 \\
\hline Batch-1.00 & 1.00 & 0.87 & 1.65 & 2.84 & $\mathrm{Na}_{1.65} \mathrm{Co}_{1.00}\left[\mathrm{Fe}(\mathrm{CN})_{6}\right]_{0.87} \cdot 2.84 \mathrm{H}_{2} \mathrm{O}$ & $R \overline{3} c$ & 7.43 & 7.43 & 17.46 \\
\hline Batch-1.33 & 1.33 & 0.90 & 1.71 & 3.00 & $\mathrm{Na}_{1.71} \mathrm{Co}_{1.00}\left[\mathrm{Fe}(\mathrm{CN})_{6}\right]_{0.90} \cdot 3.00 \mathrm{H}_{2} \mathrm{O}$ & $R \overline{3} c$ & 7.45 & 7.45 & 17.45 \\
\hline Flow-1.00 after ads. & 1.00 & & & & & $F m \overline{3} m$ & 10.16 & 10.16 & 10.16 \\
\hline
\end{tabular}

desorption test, a $\mathrm{NaCl}$ solution of $5 \mathrm{~mol} \mathrm{~L}^{-1}$ was similarly flowed for $2 \mathrm{~h}$ at a rate of $1 \mathrm{~mL} \mathrm{~min}^{-1}$.

\section{Results and discussion}

\subsection{Composition dependence}

The dependence of the chemical composition on the mixing ratio, $R_{\text {mix }}$, is presented in Table 1. For $R_{\text {mix }}<1.00, x$ is an almost equal to $R_{\text {mix }}$. The value of $y$, the number of $\mathrm{Na}^{+}$ions in NaCoHCF, also increased. In contrast, when $R_{\text {mix }}>1.00$, the chemical composition was almost unchanged, demonstrating that the composition can be controlled by changing the reaction $R_{\text {mix }}$ to $x<1$.

The crystal structure of NaCoHCF depends on the chemical composition (see Fig. S2 $\dagger$ ). When $R_{\text {mix }} \geq 1.00$, the crystal structure is rhombohedral $(R \overline{3})$, as reported. ${ }^{44,45}$ On the other hand, the structure for $R_{\mathrm{mix}}=0.50$ is unclear. Earlier reports described the space group as monoclinic $\left(P 2 / m \text { or } P 2_{1} / m\right)^{46}$ or cubic $(P m \overline{3} m) \cdot{ }^{47,48}$ In our case, the XRD pattern is explained as a mixture of $R \overline{3} c$ and $P 2_{1} / m$ structures, as shown in Table 1 . The NaCoHCF with $R_{\text {mix }}=0.67$ is also explainable as a mixture. Such a mixture could be the result of the batch synthesis because homogeneous synthesis is difficult using the batch method, resulting in the fluctuation of the chemical composition.

The BET surface areas of Batch-0.50, -0.67 , and 1.00 were evaluated to be 28,76 , and $46 \mathrm{~m}^{2} \mathrm{~g}^{-1}$, respectively. The $\mathrm{N}_{2}$ isotherms are shown in Fig. S3 in the ESI. $\dagger$ These values are much smaller than those of other Prussian blue analogs synthesized for gas adsorption. For example, that of Co $\left[\mathrm{Fe}(\mathrm{CN})_{6}\right]_{0.60}$ was $848 \mathrm{~m}^{2} \mathrm{~g}^{-1}$. The smaller surface area originated from the inclusion of $\mathrm{Na}^{+}$cations. Because the interstitial sites of NaCoHCF are fully or partially occupied by $\mathrm{Na}^{+}$, it would be impossible for $\mathrm{N}_{2}$ to penetrate into the $\mathrm{NaCoHCF}$ lattice. This presumption is also supported by the fact that the averaged pore diameter is comparable to the particle size, as shown later in the analysis of Flow-1.00.

Fig. 2(a) shows that the $\mathrm{NH}_{4}{ }^{+}$adsorption capacity improved with increasing $R_{\text {mix }}$. The amount of adsorbed ammonia of Batch-2.00 is about twice that of Batch-0.5. Fig. 2(b) shows that the amount of $\mathrm{Na}^{+}$from the adsorbent has an almost linear correlation with the $\mathrm{NH}_{4}{ }^{+}$adsorption amount, indicating the $\mathrm{NH}_{4}{ }^{+}$adsorption occurred through ion exchange with $\mathrm{Na}^{+}$. These results demonstrate that the increase in the $\mathrm{Na}^{+}$ composition in NaCoHCF enhances the $\mathrm{NH}_{4}{ }^{+}$adsorption capacity, and that NaCoHCF retains its structure even after long-term shaking in water. However, for $R_{\text {mix }}>1.00$, the adsorption capacity increased by only $2.9-3.9 \%$ from $R_{\text {mix }}=$ 1.00 because the upper limit of $x$ is 1.0.

\subsection{Detailed study with flow-synthesized NaCoHCF with $\boldsymbol{R}_{\text {mix }}$ $=1.00$}

Based on results of the composition dependence of the $\mathrm{NH}_{4}{ }^{+}$ capacity, we chose to conduct a detailed study of NaCoHCF-NPs with $R_{\text {mix }}=1.00$ because we obtained the desired chemical

\section{(a)}

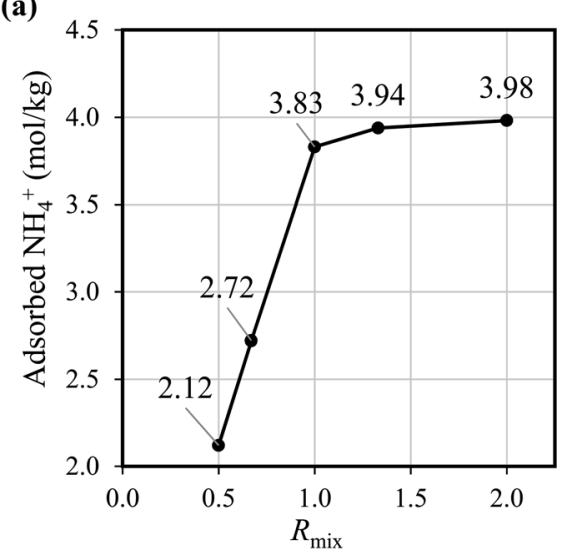

(b)

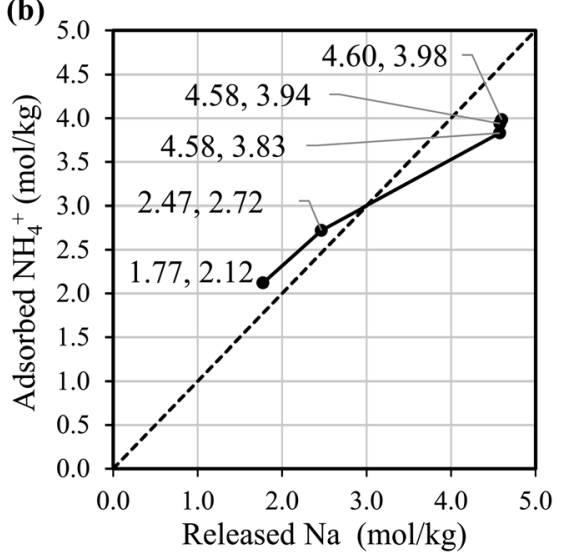

Fig. 2 (a) Amount of adsorbed $\mathrm{NH}_{4}{ }^{+}$by the batch-synthesized $\mathrm{NaCoHCF}$ with different compositions. (b) The relationship between adsorbed $\mathrm{NH}_{4}{ }^{+}$and released $\mathrm{Na}^{+}$. The adsorption experiment was conducted at initial $\mathrm{NH}_{4}{ }^{+}$of $90 \mathrm{mg} \mathrm{L}^{-1}, 30{ }^{\circ} \mathrm{C}$, and at $600 \mathrm{rpm}$ for $3 \mathrm{~h}$. 
composition by using this value of $R_{\text {mix }}$ and because it showed sufficiently high capacity. For our detailed study, we used the flow-synthesized sample, Flow-1.00, to avoid the fluctuation of the chemical composition and particle size. Table 1 shows that the chemical composition of Flow-1.00 is almost identical to that of Batch-1.00. The adsorption kinetics was studied at an initial $\mathrm{NH}_{4}{ }^{+}$concentration of $500 \mathrm{mg} \mathrm{L}^{-1}, 30{ }^{\circ} \mathrm{C}$, and at $600 \mathrm{rpm}$ for $8 \mathrm{~h}$ (see Fig. $\mathrm{S} 4 \dagger$ ). The results showed that the $\mathrm{NH}_{4}{ }^{+}$ adsorption was almost completed in $30 \mathrm{~min}$. Such fast adsorption is similar to the case of KCuHCF. ${ }^{15}$

Using BET analysis, we estimated the surface area to be 53 $\mathrm{m}^{2} \mathrm{~g}^{-1}$, which is also comparable to that of Batch-1.00, $46 \mathrm{~m}^{2}$ $\mathrm{g}^{-1}$. As described before, this value is not very high because the interstitial sites of $\mathrm{NaCoHCF}$ are filled with $\mathrm{Na}^{+}$, preventing the penetration of $\mathrm{N}_{2}$ into the porous network in the crystal. The average pore size was estimated to $31 \mathrm{~nm}$ for Flow-1.00, consistent with the size of the crystallites, as shown later.

After $\mathrm{NH}_{4}{ }^{+}$adsorption, the crystal structure was maintained, except for a slight trigonal distortion. Fig. 3 shows the XRD patterns obtained before and after $\mathrm{NH}_{4}{ }^{+}$adsorption. Some splitting of the Bragg peaks is apparent. The slight structural transformation observed is the same as that in the case of ion exchange between $\mathrm{Na}^{+}$and $\mathrm{K}^{+}{ }^{45}$ Before adsorption, NaCoHCF had a rhombohedral $(R \overline{3} c)$ structure. However, after $\mathrm{NH}_{4}{ }^{+}$ adsorption, it changed to a cubic lattice $(F m \overline{3} m ; Z=4)$. Thus, the ion exchange reversibly changed the structure.

The structural change also influenced the shape and size of the interstitial sites in which $\mathrm{Na}^{+}$or $\mathrm{NH}_{4}{ }^{+}$are located. The lattice parameters of the crystal are shown in Table 1. A schematic view of the relationship between the interstitial site and the lattice distortion is shown in Fig. 4 . Note that the crystal symmetry is different before and after the $\mathrm{NH}_{4}{ }^{+}$adsorption. Before adsorption, the lattice has the rhombohedral symmetry with slight distortion from the cubic lattice. That is, it was compressed along the $(1,1,1)$ direction. In contrast, after adsorption, the crystal maintained the cubic structure. This difference is consistent with previous reports of the ion exchange between $\mathrm{Na}^{+}$and $\mathrm{K}^{+}$but not $\mathrm{NH}_{4}{ }^{+} \cdot{ }^{45}$

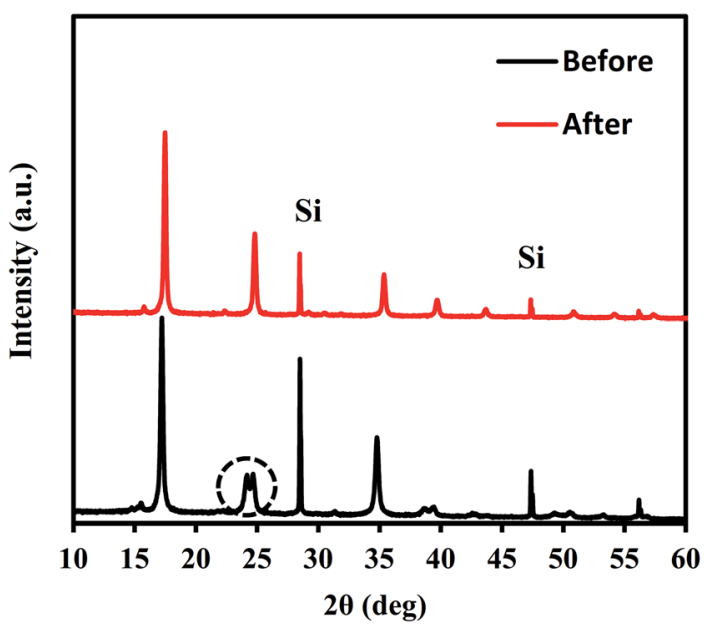

Fig. 3 XRD patterns for Flow-1.0 with before and after adsorption with an aqueous $\mathrm{NH}_{4} \mathrm{Cl}$ solution containing $500 \mathrm{mg} \mathrm{L}^{-1}$ of $\mathrm{NH}_{4}^{+}$.

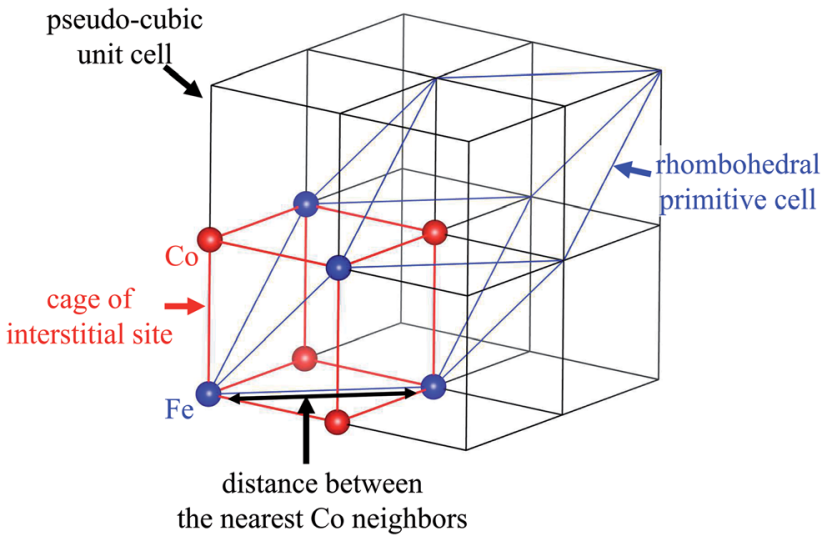

Fig. 4 Schematic view of the relationship between the cage of the interstitial site, the cubic unit cell, and the primitive cell of the rhombohedral symmetry.

Because the symmetry of the crystal is different before and after $\mathrm{NH}_{4}{ }^{+}$adsorption, we investigated the distance between the nearest Co neighbors and the volume of the (pseudo)-cubic cage of the interstitial site to evaluate the changes to the interstitial sites. Before $\mathrm{NH}_{4}{ }^{+}$adsorption, the distance between the nearest Co neighbors was calculated as the length of the unit vector of the rhombohedral primitive cell, 7.24 $\AA$. On the other hand, after $\mathrm{NH}_{4}{ }^{+}$adsorption, the separation was reduced to $7.18 \AA$, resulting in reduction in the volume of the cage from 138 to 131 $\AA^{3}$. It is interesting that the cage became smaller although the ionic radius of $\mathrm{NH}_{4}{ }^{+}$is larger than that of $\mathrm{Na}^{+}$. This could be due to the difference in the $\mathrm{H}_{2} \mathrm{O}$ accompanying the cations. Because the interaction with $\mathrm{H}_{2} \mathrm{O}$ is stronger with $\mathrm{Na}^{+}$than that with $\mathrm{NH}_{4}{ }^{+}$. Therefore, before $\mathrm{NH}_{4}{ }^{+}$adsorption, $\mathrm{H}_{2} \mathrm{O}$ is adsorbed along with $\mathrm{Na}^{+}$, even if cage expansion is energetically disadvantageous. This is consistent with the previous studies of the electrochemical injection of $\mathrm{Na}^{+}$into copper hexacyanoferrate thin films. ${ }^{49}$

No nanoparticle degradation occurred during adsorption. The crystallite sizes estimated by Scherrer analysis of the XRD patterns (Fig. 3) before and after sorption were, respectively, 37.9 and $51.7 \mathrm{~nm}$. This result is consistent with the SEM images in Fig. 5. The particle sizes estimated using SEM images were 33 \pm 10 and $47 \pm 13 \mathrm{~nm}$. The data indicate no degradation, but there is a possibility of some particle growth. The reason for the growth remains unclear, but it could be due to the immobilization of the $\mathrm{Co}^{2+}$ and $\left[\mathrm{Fe}(\mathrm{CN})_{6}\right]^{4-}$ ions eluted from the adsorbent onto the other part of the adsorbent. If so, the adsorbent would retain the eluted species. The surface morphology in SEM images shows no marked change after adsorption. Furthermore, we also evaluated the release of $\mathrm{CN}^{-}$after adsorption. The concentration of $\mathrm{CN}^{-}$in solution was only $0.33 \mathrm{mg} \mathrm{L}^{-1}$, suffi-

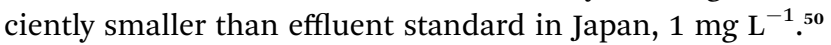

Fig. 6 shows the $\mathrm{NH}_{4}{ }^{+}$adsorption isotherms in aqueous $\mathrm{NH}_{4} \mathrm{Cl}$ solution and that in aqueous saline solution. In the saline solution, the concentration of the $\mathrm{Na}^{+}$solution was set to $9350 \mathrm{mg} \mathrm{L}^{-1}$, the same as that of artificial seawater. The curves fit to the Langmuir, Freundlich, and Markham-Benton 
(a) Before $\mathrm{NH}_{4}^{+}$-adsorption

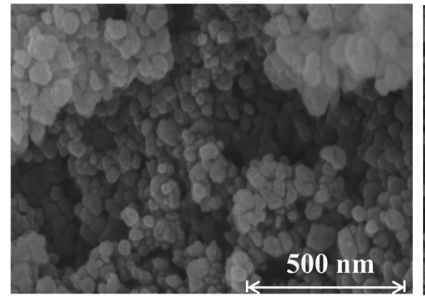

(b) After $\mathrm{NH}_{4}{ }^{+}$-adsorption

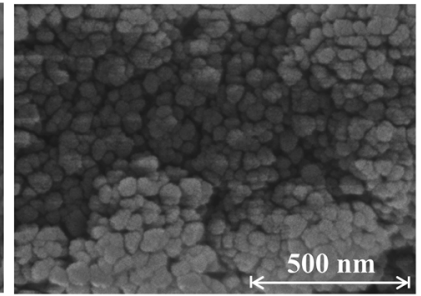

Fig. 5 SEM images for Flow-1.00 (a) before and (b) after adsorption of $500 \mathrm{mg} \mathrm{L}^{-1} \mathrm{NH}_{4}^{+}$in pure water solution.

equations are also shown in Fig. 6. The fitting parameters for each equation are shown in Table 2. Concerning the Langmuir and Freundlich equations, individual fitting parameters were obtained for the $\mathrm{NH}_{4} \mathrm{Cl}_{(\mathrm{aq})}$ and saline solutions.

The Langmuir equation is given by

$$
\frac{C_{\mathrm{e}}}{q_{\mathrm{e}}}=\frac{1}{q_{\max }} C_{\mathrm{e}}+\frac{1}{K q_{\max }}
$$

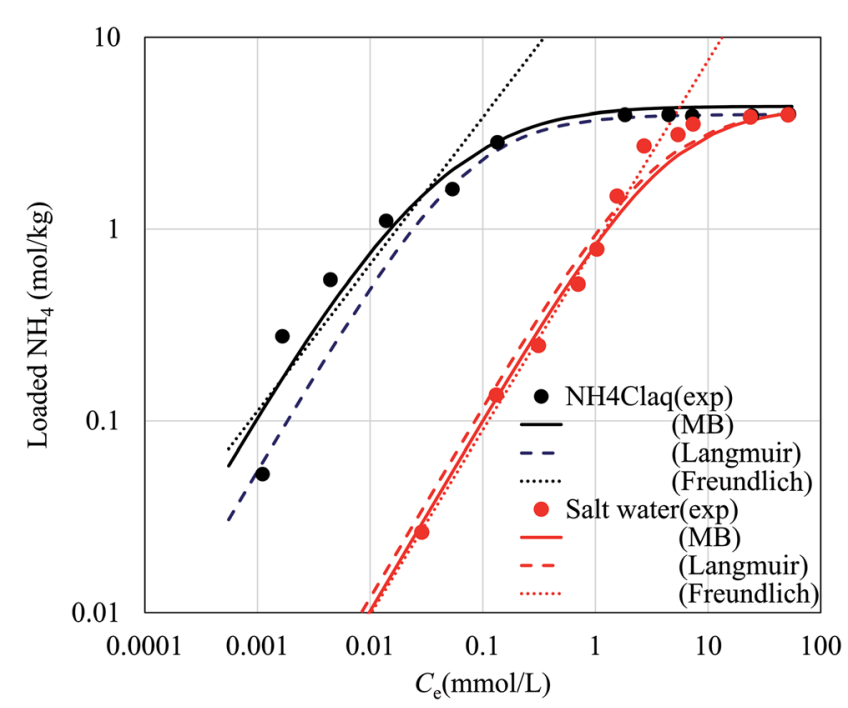

Fig. 6 Adsorption behavior of $\mathrm{NH}_{4}^{+}$by the flow-synthesized $\mathrm{NaCoHCF}$ with $R_{\text {mix }}=1.00$ with curves fit to the Markham-Benton (solid lines), Langmuir (broken line), and Freundlich (dotted line) equations. The experimental points are represented by closed circles. Black and red symbols represent $\mathrm{NH}_{4} \mathrm{Cl}$ aqueous solution and salt water, respectively. where $C_{\mathrm{e}}, q_{\mathrm{e}}, q_{\max }$, and $K$ respectively represent the $\mathrm{NH}_{4}{ }^{+}$ concentration in solution at equilibrium, loaded $\mathrm{NH}_{4}{ }^{+}$in the adsorbent, maximum adsorption capacity, and the equilibrium constant. The same data are also shown with other axes in Fig. S5, $\uparrow$ and the adsorption behavior fits the Langmuir equation well. We also carried out fitting to the Freundlich equation,

$$
q_{\mathrm{e}}=K_{\mathrm{f}} \mathrm{C}^{1 / n}
$$

For the Freundlich equation, only the region where the loaded $\mathrm{NH}_{4}{ }^{+}$concentration was less than $1.95 \mathrm{~mol} \mathrm{~kg}^{-1}$, about a half the maximum capacity, was considered because the Freundlich equation is only suitable far from saturated loading. However, in this region, the Freundlich equation also well reproduced the experimental data.

In the fitting of the Langmuir or Freundlich equations, we used different parameters for $\mathrm{NH}_{4} \mathrm{Cl}_{(\mathrm{aq})}$ and the salt solutions because the effect of the coexistent $\mathrm{Na}^{+}$ions can only be modeled by changing the fitting parameters. For a more quantitative evaluation of the effect of the coexistent $\mathrm{Na}^{+}$ions, we also considered the Markham-Benton model for a solution with multi-alkali cations. As a type of extended Langmuir equation, the Markham-Benton equation ${ }^{51}$ was used to examine adsorption isotherms for multiple components to estimate the ease of desorption of the adsorbents. The results also provide some understanding of the selectivity of the sorbents for some ions. The Markham-Benton equation is

$$
q_{\mathrm{e}}=\frac{q_{\max } K C_{\mathrm{e}}}{1+K C_{\mathrm{e}}+K^{\prime} C_{\mathrm{e}}^{\prime}},
$$

where $C_{\mathrm{e}}, q_{\mathrm{e}}$, and $K$ respectively represent the $\mathrm{NH}_{4}^{+}$ion concentration in equilibrium, the adsorption capacity, and the equilibrium constant. $C_{\mathrm{e}}^{\prime}$ and $K^{\prime}$ respectively denote the $\mathrm{Na}^{+}$ion concentration in equilibrium and the equilibrium constant.

Considering the $\mathrm{Na}^{+}$-ion exchange for $\mathrm{NH}_{4}{ }^{+}$ions, i.e., even in $\mathrm{NH}_{4} \mathrm{Cl}$ aqueous solution, an equal amount of $\mathrm{Na}^{+}$ions would be exchanged out, adversely affecting the adsorption capacity. When we consider both sources of $\mathrm{Na}^{+}$ions (those in NaCoHCF and that in the solution), the equation can be expressed by as $q_{\mathrm{e}}=$

$$
\frac{-\left(1+K C_{\mathrm{e}}+K^{\prime} C_{0}^{\prime}\right)+\sqrt{\left(1+K C_{\mathrm{e}}+K^{\prime} C_{0}^{\prime}\right)^{2}+4 K^{\prime} \frac{m}{V} q_{\max } K C_{\mathrm{e}}}}{2 K^{\prime} \frac{m}{V}},
$$

\begin{tabular}{|c|c|c|c|c|c|c|c|c|c|c|}
\hline \multicolumn{4}{|l|}{ Langmuir } & \multicolumn{4}{|l|}{ Freundlich } & \multirow{2}{*}{\multicolumn{3}{|c|}{$\begin{array}{l}\text { Markham-Benton } \\
\mathrm{NH}_{4} \mathrm{Cl}_{(\mathrm{aq})} \text { \& saline }\end{array}$}} \\
\hline \multicolumn{2}{|l|}{$\mathrm{NH}_{4} \mathrm{Cl}_{(\mathrm{aq})}$} & \multicolumn{2}{|l|}{ Saline } & \multicolumn{2}{|l|}{$\mathrm{NH}_{4} \mathrm{Cl}_{(\mathrm{aq})}$} & \multicolumn{2}{|l|}{ Saline } & & & \\
\hline $\begin{array}{l}K \\
\left(\mathrm{~L} \mathrm{~mol}^{-1}\right)\end{array}$ & $\begin{array}{l}q_{\max } \\
\left.(\mathrm{mol} \mathrm{kg})^{-1}\right)\end{array}$ & $\begin{array}{l}K \\
\left(\mathrm{~L} \mathrm{~mol}^{-1}\right)\end{array}$ & $\begin{array}{l}q_{\max } \\
\left(\mathrm{mol} \mathrm{kg}^{-1}\right)\end{array}$ & $\begin{array}{l}K_{\mathrm{f}} \\
\left(\mathrm{mol} \mathrm{kg}^{-1}\right)\end{array}$ & $1 / n$ & 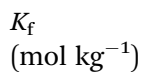 & $1 / n$ & $\begin{array}{l}q_{\max } \\
\left(\mathrm{mol} \mathrm{kg}^{-1}\right)\end{array}$ & $\begin{array}{l}K \\
\left(\mathrm{~L} \mathrm{~mol}^{-1}\right)\end{array}$ & $\begin{array}{l}K^{\prime} \\
\left(\mathrm{L} \mathrm{mol}^{-1}\right)\end{array}$ \\
\hline 13.99 & 3.97 & 0.28 & 4.28 & 22.27 & 0.77 & 0.82 & 0.96 & 4.36 & 24.84 & 0.26 \\
\hline
\end{tabular}

Table 2 The fitting parameters with the Langmuir, Freundlich, and the Markham-Benton equations for the $\mathrm{NH}_{4}{ }^{+}$adsorption using the flowsynthesized $\mathrm{NaCoHCF}$ with $R_{\text {mix }}=1.00$ 
where $C_{0}^{\prime}, m$, and $V$ respectively denote the initial $\mathrm{Na}^{+}$ion concentration in solutions, adsorbent mass, and solution volume.

The fitting parameters, $q_{\max }, K$, and $K^{\prime}$, are shown in Table 2. Fig. 6 shows that the experimental data were well fitted using the Markham-Benton model. Again, with the Markham-Benton model, we use the same parameter set for $\mathrm{NH}_{4} \mathrm{Cl}_{(\mathrm{aq})}$ and the saline solutions. A selectivity factor, $\alpha$, defined by the ratio of equilibrium constants for $\mathrm{NH}_{4}{ }^{+}$to that for $\mathrm{Na}^{+}$was calculated to be $\alpha=96.2$, indicating the high selectivity of $\mathrm{NH}_{4}{ }^{+}$against $\mathrm{Na}^{+}$.

Such high selectivity is expected to lead to extremely high capacity, even in an aqueous saline solution. To clarify the high capacity of NaCoHCF among the various adsorbents, we used two approaches. First, we surveyed and compared results with those of earlier studies, and we also conducted experimental investigations to assess the adsorption capacity of adsorbents in identical conditions. For the literature survey, we picked reports of adsorption tests carried out using a batch style because column-style tests generally report higher capacities, rendering a comparison of results difficult between batch-style tests and column tests.

Information from earlier studies is presented in Table 3 for the adsorption capacity of adsorbents for $\mathrm{NH}_{4}{ }^{+}$from aqueous solution in batch style, indicating that the NaCoHCF (Flow-1.00) capacity exceeds that of all earlier reports. However, as described above, SAC resins have been reported to have high capacities, although these values were achieved using the column method without coexistent cations. For comparison under the same conditions, we evaluated the respective adsorption capacities of a synthetic zeolite, Amberlite IR-120(H) as a representative SAC, sepiolite, and NaCoHCF (Flow-1.00). Even in the $\mathrm{NH}_{4} \mathrm{Cl}$ aqueous solution (500 mg $\mathrm{L}^{-1}-\mathrm{NH}_{4}$ ), NaCoHCF exhibited the highest capacity, whereas Amberlite adsorbed only $1.29 \mathrm{~mol} \mathrm{~kg}^{-1}$. This result is due to the difference between column and batch tests. The capacity evaluated with a batch test sometimes larger than that with a column test, and

Table $3 \mathrm{NH}_{4}{ }^{+}$adsorption capacities of adsorbents in aqueous solutions evaluated in batch experiments reported in the literature

\begin{tabular}{lll}
\hline & $\begin{array}{l}\text { Maximum } \\
\text { capacity } \\
\left(\mathrm{mol} \mathrm{kg}^{-1}\right)\end{array}$ & Ref. \\
\hline Adsorbent & 1.54 & 12 \\
\hline $\begin{array}{l}\text { Alkaline activated and lanthanum- } \\
\text { impregnated zeolite }\end{array}$ & & \\
$\begin{array}{l}\text { Sodium hydroxide modified zeolite } \\
\text { mordenite }\end{array}$ & 3.0 & 13 \\
Natural zeolite & 2.36 & 14 \\
Modified natural zeolite & 2.14 & 14 \\
Dowex 50w-x8 & 2.64 & 52 \\
Sepiolite & 3.70 & 53 \\
Carbon nanotubes & 0.95 & 54 \\
Poly ligand exchanger resin & 2.51 & 55 \\
Cation exchange resin & 0.81 & 56 \\
KCuHCF & 1.94 & 15 \\
NaCoHCF (Flow-1.00) & 4.36 & This \\
& & study
\end{tabular}

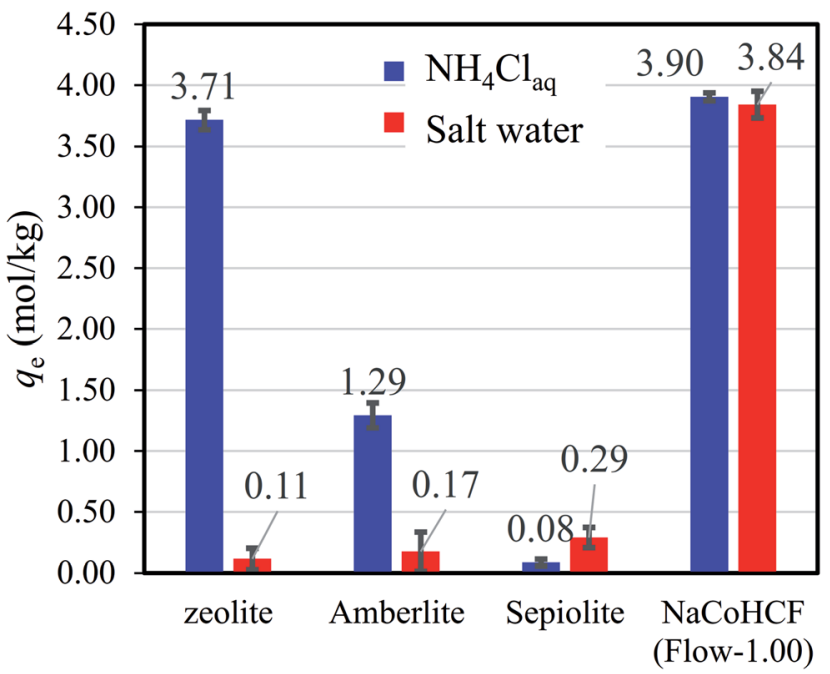

Fig. 7 Adsorption capacity of various adsorbents in $\mathrm{NH}_{4} \mathrm{Cl}$ aqueous solution $\left(500 \mathrm{mg} \mathrm{L}^{-1}-\mathrm{NH}_{4}{ }^{+}\right)$and saline solution with a concentration fixed at $9350 \mathrm{mg} \mathrm{L}^{-1}-\mathrm{Na}$.

sometimes smaller. When the contact time is short in the column test, the capacity would be underestimated. On the other hand, with bad selectivity of the adsorbent, the capacity in a batch test would be smaller than that in a column test. In the batch test, the cations $\mathrm{A}^{+}$are exchanged into the solution on the $\mathrm{NH}_{4}{ }^{+}$adsorption and remain in the system, resulting in the possibility of the reverse reaction $\left(\mathrm{A}^{+}\right.$adsorption- $\mathrm{NH}_{4}{ }^{+}$ desorption).

The benefits of NaCoHCF were amplified in the case of aqueous saline solution with $9350 \mathrm{mg} \mathrm{L}^{-1}$-Na and $500 \mathrm{mg} \mathrm{L}^{-1}$. $\mathrm{NH}_{4}$. Fig. 7 shows that NaCoHCF has an adsorption capacity that is almost identical to that of the case without $\mathrm{Na}^{+}$, whereas the other adsorbents showed little adsorption.

Although our main aim, the preparation of an $\mathrm{NH}_{4}$-adsorbent with high capacity and high selectivity, has been achieved, the recyclability of the adsorbent is also important for practical use. Therefore, finally, we demonstrate the potential for recyclability by attempting desorption tests. Fig. 8 shows that the adsorption-desorption-adsorption process was confirmed by measuring the infrared absorption corresponding to $\mathrm{NH}_{4}^{-}$ vibration mode at around $1415 \mathrm{~cm}^{-1} \cdot{ }^{15}$ Using the continuous flow of $\mathrm{NaCl}$ solution for desorption, the peak height was found to decrease to $28 \%$ the original value before flow, indicating the potential for NaCoHCF recyclability. Next, further study on the sorption performances, including the column sorption, quantitatively reusability test would be conducted.

Finally, we mention concerning the cost of the materials. As mentioned above, NaCoHCF is synthesized only mixing two solutions immediately, resulting in the suppression of the manufacturing cost. For $\mathrm{NH}_{4}$ removal from salt water, NaCoHCF would be cost effective in comparison with Amberlites and zeolites, despite the utilization of the cobalt, one of the rare metals. This is because the amount of the adsorbent can be drastically decreased with its high selectivity. 

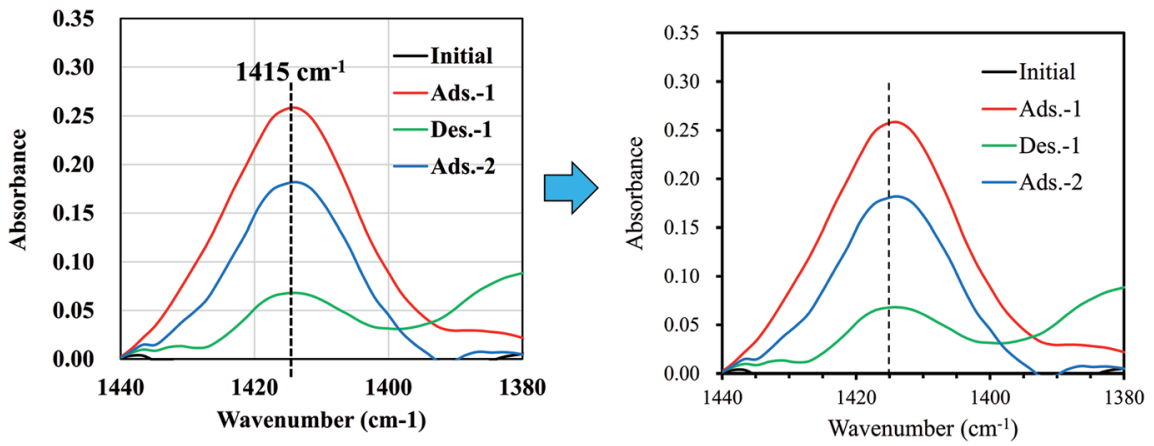

Fig. 8 FT-IR spectra showing the changes in the peak-height of $\mathrm{NH}_{4}^{+}$adsorbed onto Flow-1.00 with sorption and desorption.

\section{Conclusions}

$\mathrm{Na}_{y} \mathrm{Co}\left[\mathrm{Fe}(\mathrm{CN})_{6}\right]_{x} \cdot z \mathrm{H}_{2} \mathrm{O} \quad(\mathrm{NaCoHCF})$ was synthesized using a batch method and various chemical compositions. Synthesis was also carried out using a flow method and a fixed composition. The adsorption capacity increased as the number of $\left[\mathrm{Fe}(\mathrm{CN})_{6}\right]$ vacancies decreased and the material was stable in water. Such stability is unlike that of copper hexacyanoferrate. We compared the $\mathrm{NH}_{4}{ }^{+}$adsorption performance with other high-capacity adsorbents under the same conditions: zeolites, Amberlite ion-exchange resin, and sepiolite. The results show that $\mathrm{NaCoHCF}$ exhibited the highest capacity in $\mathrm{NH}_{4} \mathrm{Cl}$ aqueous solution. Using aqueous saline solutions with $\mathrm{a} \mathrm{Na}^{+}$ion concentration of $9350 \mathrm{mg} \mathrm{L}^{-1}$, the benefits of using NaCoHCF are enhanced drastically. The Markham-Benton model revealed the high selectivity for $\mathrm{NH}_{4}{ }^{+}$against coexisting $\mathrm{Na}^{+}$. In addition, ammonium desorption from the adsorbent (enabling recycling) was demonstrated using an $\mathrm{NaCl}$ aqueous solution.

\section{Author contributions}

The manuscript was written through contributions of all authors. All authors have given approval to the final version of the manuscript.

\section{Conflicts of interest}

The authors declare no competing financial interest.

\section{Abbreviations}

SAC

MHCFs

NaCoHCF-NPs
Strong acid cation

Metal hexacyanoferrates

NaCoHCF-nanoparticles

\section{Acknowledgements}

The authors thank Ms Keiko Noda for the SEM training given to Y. J. The authors also thank Ms Ying Wang for the valuable discussion related to the Langmuir equation.

\section{References}

1 A. M. Fan and V. E. Steinberg, Regul. Toxicol. Pharmacol., 1996, 23, 35-43.

2 J. N. Galloway, J. D. Aber, J. W. Erisman, S. P. Seizinger, R. W. Howarth, E. B. Cowling and B. J. Cosby, Bioscience, 2003, 53, 341.

3 R. W. Howarth, Harmful Algae, 2008, 8, 14-20.

4 L. Olsen, M. Holmer and Y. Olsen, Perspectives of nutrient emission from fish aquaculture in coastal waters, 2008.

5 IPCC, working group I, Climate change 2013: The physical Science Basis, http:/www.climatechange2013.org/images/ uploads/WG1AR5_CLAsLAsREsAnnexEditors_FINAL.pdf, (accessed 5 October 2018).

6 Aquatic Life Ambient Water Quality Criteria for Ammonia Freshwater (2013) Fact Sheet, https://www.epa.gov/sites/ production/files/2015-08/documents/fact_sheet_aquatic-lifeambient-water-quality-criteria-for-ammonia-freshwater2013.pdf, accessed 1 May 2018.

7 The Environment (Protection) Rules, http://cpcb.nic.in/ GeneralStandards.pdf, accessed 1 May 2018.

8 Maximum Allowable Discharge Concentrations for Other Pollutants in China, https://chinawaterrisk.org/wp-content/ uploads/2011/05/Maximum-Allowable-Discharge-

Concentrations-For-Other-Pollutants-in-China.pdf, accessed 1 May 2018.

9 H. Chen, W. Wang, L. Xue, C. Chen, G. Liu and R. Zhang, Energy Fuels, 2016, 30, 5749-5757.

10 O. Yenigün and B. Demirel, Process Biochem., 2013, 48, 901911.

11 A. Malovanyy, H. Sakalova, Y. Yatchyshyn, E. Plaza and M. Malovanyy, Desalination, 2013, 329, 93-102.

12 Y. He, H. Lin, Y. Dong, Q. Liu and L. Wang, Chemosphere, 2016, 164, 387-395.

13 J. P. Soetardji, J. C. Claudia, Y.-H. Ju, J. A. Hriljac, T.-Y. Chen, F. E. Soetaredjo, S. P. Santoso, A. Kurniawan and S. Ismadji, RSC Adv., 2015, 5, 83689-83699.

14 D. Guaya, C. Valderrama, A. Farran, C. Armijos and J. L. Cortina, Chem. Eng. J., 2015, 271, 204-213.

15 D. Parajuli, H. Noguchi, A. Takahashi, H. Tanaka and T. Kawamoto, Ind. Eng. Chem. Res., 2016, 55, 6708-6715. 
16 X. Li, J. Wang, A. I. Rykov, V. K. Sharma, H. Wei, C. Jin, X. Liu, M. Li, S. Yu, C. Sun and D. D. Dionysiou, Catal. Sci. Technol., 2015, 5, 504-514.

17 X. Li, A. I. Rykov, B. Zhang, Y. Zhang and J. Wang, Catal. Sci. Technol., 2016, 6, 7486-7494.

18 X. Li, A. I. Rykov and J. Wang, Catal. Commun., 2016, 77, 3236.

19 V. D. Neff, J. Electrochem. Soc., 1985, 132, 1382.

20 M. Okubo, D. Asakura, Y. Mizuno, J.-D. Kim, T. Mizokawa, T. Kudo and I. Honma, J. Phys. Chem. Lett., 2010, 1, 20632071.

21 M. Takachi, T. Matsuda and Y. Moritomo, Appl. Phys. Express, 2013, 6, 4-7.

22 M. Pasta, R. Y. Wang, R. Ruffo, R. Qiao, H.-W. Lee, B. Shyam, M. Guo, Y. Wang, L. A. Wray, W. Yang, M. F. Toney and Y. Cui, J. Mater. Chem. A, 2016, 4, 4211-4223.

23 V. D. Neff, J. Electrochem. Soc., 1978, 125, 886-887.

24 L.-C. Chen, Y.-H. Huang and K.-C. Ho, J. Solid State Electrochem., 2002, 7, 6-10.

25 R. J. Kulesza, M. A. Malik, K. Miecznikowski, A. Wolkiewicz and P. J. Kulesza, J. Electrochem. Soc., 1996, 143, L10.

26 T.-C. C. Liao, W.-H. H. Chen, H.-Y. Y. Liao and L.-C. C. Chen, Sol. Energy Mater. Sol. Cells, 2016, 145, 26-34.

27 E. Kholoud, H. Watanabe, A. Takahashi, M. M. Emara, B. A. Abd-El-Nabey, M. Kurihara, K. Tajima and T. Kawamoto, J. Mater. Chem. C, 2017, 5, 8921-8926.

28 R. Pauliukaite, M. Florescu and C. M. A. Brett, J. Solid State Electrochem., 2005, 9, 354-362.

29 W.-R. Cai, G.-Y. Zhang, T. Song, X.-J. Zhang and D. Shan, Electrochim. Acta, 2016, 198, 32-39.

30 S. S. Kaye and J. R. Long, J. Am. Chem. Soc., 2005, 127, 65066507.

31 A. Takahashi, H. Tanaka, D. Parajuli, T. Nakamura, K. Minami, Y. Sugiyama, Y. Hakuta, S. Ohkoshi and T. Kawamoto, J. Am. Chem. Soc., 2016, 138, 6376-6379.

32 L. Hu, P. Zhang, Q.-W. Chen, J.-Y. Mei and N. Yan, RSC Adv., 2011, 1, 1574.

33 O. Sato, T. Iyoda, A. Fujishima and K. Hashimoto, Science (80- ), 1996, 272, 704-705.

34 S. I. Ohkoshi and K. Hashimoto, J. Am. Chem. Soc., 1999, 121, 10591-10597.

35 V. Escax, a. Bleuzen, C. Cartier dit Moulin, F. Villain, a. Goujon, F. Varret and M. Verdaguer, J. Am. Chem. Soc., 2001, 123, 12536-12543.
36 A. Takahashi, N. Minami, H. Tanaka, K. Sue, K. Minami, D. Parajuli, K.-M. Lee, S. Ohkoshi, M. Kurihara and T. Kawamoto, Green Chem., 2015, 17, 4228-4233.

37 D. Parajuli, A. Kitajima, A. Takahashi, H. Tanaka, H. Ogawa, Y. Hakuta, K. Yoshino, T. Funahashi, M. Yamaguchi, M. Osada and T. Kawamoto, J. Environ. Radioact., 2015, 151, 233-237.

38 a. Nilchi, R. Saberi, M. Moradi, H. Azizpour and R. Zarghami, Chem. Eng. J., 2011, 172, 572-580.

39 J. Causse, A. Tokarev, J. Ravaux, M. Moloney, Y. Barré and A. Grandjean, J. Mater. Chem. A, 2014, 2, 9461.

40 M. Ishizaki, S. Akiba, A. Ohtani, Y. Hoshi, K. Ono, M. Matsuba, T. Togashi, K. Kananizuka, M. Sakamoto, A. Takahashi, T. Kawamoto, H. Tanaka, M. Watanabe, M. Arisaka, T. Nankawa and M. Kurihara, Dalton Trans., 2013, 42, 16049-16055.

41 E. R. Nightingale, J. Phys. Chem., 1959, 63, 1381-1387.

42 A. Takahashi, H. Tanaka, K. Minami, K. Noda, M. Ishizaki, M. Kurihara, H. Ogawa and T. Kawamoto, RSC Adv., accepted.

43 P. Scherrer, Nachr. Ges. Wiss. Göttingen, 1918, 26, 98.

44 Y. Moritomo, K. Igarashi, T. Matsuda and J. Kim, J. Phys. Soc. Jpn., 2009, 78, 074602.

45 T. Matsuda, J. Kim and Y. Moritomo, J. Am. Chem. Soc., 2010, 132, 12206-12207.

46 M. Avila, L. Reguera, J. Rodríguez-Hernández, J. Balmaseda and E. Reguera, J. Solid State Chem., 2008, 181, 2899-2907.

47 S. Adak, L. L. Daemen, M. Hartl, D. Williams, J. Summerhill and H. Nakotte, J. Solid State Chem., 2011, 184, 2854-2861.

48 S. Adak, M. Hartl, L. Daemen, E. Fohtung and H. Nakotte, J. Electron Spectrosc. Relat. Phenom., 2017, 214, 8-19.

49 M. Asai, A. Takahashi, K. Tajima, H. Tanaka, M. Ishizaki, M. Kurihara and K. Tohru, RSC Adv., submitted.

50 National Effluent Standards in Japan, https:/www.env.go.jp/ en/water/wq/nes.html, accessed 21 September 2018.

51 E. C. Markham and A. F. Benton, J. Am. Chem. Soc., 1931, 53, 497-507.

52 T. C. Jorgensen and L. R. Weatherley, Water Res., 2003, 37, 1723-1728.

53 S. Balci, Water Res., 2004, 38, 1129-1138.

54 O. Moradi and K. Zare, Fullerenes, Nanotub. Carbon Nanostructures, 2013, 21, pp. 449-459.

55 Q. Chen, K. Zhou, Y. Chen, A. Wang and F. Liu, RSC Adv., 2017, 7, 12812-12823.

56 N. Imchuen, Y. Lubphoo, J.-M. Chyan, S. Padungthon and C.-H. Liao, Sustainable Environ. Res., 2016, 26, 156-160. 